\title{
Impact of Diabetes in Patients Diagnosed With COVID-19
}

\begin{abstract}
Mohamed Abu-Farha ${ }^{1 \dagger}$, Fahd Al-Mulla ${ }^{2 *}$, Thangavel Alphonse Thanaraj ${ }^{2 \dagger}$, Sina Kavalakatt ${ }^{1}$, Hamad Ali ${ }^{2,3}$, Mohammed Abdul Ghani ${ }^{4}$ and Jehad Abubaker ${ }^{1 *}$

1 Department of Biochemistry and Molecular Biology, Dasman Diabetes Institute, Dasman, Kuwait, ${ }^{2}$ Department of Genetics and Bioinformatics, Dasman Diabetes Institute, Dasman, Kuwait, ${ }^{3}$ Department of Medical Laboratory Sciences, Faculty of Allied Health Sciences, Health Sciences Center, Kuwait University, Jabriya, Kuwait, ${ }^{4}$ Diabetes Division, University of Texas Health Science Center at San Antonio, San Antonio, TX, United States
\end{abstract}

COVID-19 is a disease caused by the coronavirus SARS-CoV-2 (Severe Acute Respiratory Syndrome Coronavirus-2), known as a highly contagious disease, currently affecting more than 200 countries worldwide. The main feature of SARS-CoV-2 that distinguishes it from other viruses is the speed of transmission combined with higher risk of mortality from acute respiratory distress syndrome (ARDS). People with diabetes mellitus (DM), severe obesity, cardiovascular disease, and hypertension are more likely to get infected and are at a higher risk of mortality from COVID-19. Among elderly patients who are at higher risk of death from COVID-19, 26.8\% have DM. Although the reasons for this increased risk are yet to be determined, several factors may contribute to type-2 DM patients' increased susceptibility to infections. A possible factor that may play a role in increasing the risk in people affected by diabetes and/or obesity is the impaired innate and adaptive immune response, characterized by a state of chronic and low-grade inflammation that can lead to abrupt systemic metabolic alteration. SARS patients previously diagnosed with diabetes or hyperglycemia had higher mortality and morbidity rates when compared with patients who were under metabolic control. Similarly, obese individuals are at higher risk of developing complications from SARS-CoV-2. In this review, we will explore the current and evolving insights pertinent to the metabolic impact of coronavirus infections with special attention to the main pathways and mechanisms that are linked to the pathophysiology and treatment of diabetes.

\footnotetext{
Keywords: coronavirus disease (COVID-19), type 2 diabetes, angiotensin converting enzyme2 (ACE2), Furin, transmembrane protease, serine 2 (TMPRSS2), metformin, interferon induced membrane (IFITM3)
}

Received: 16 July 2020 Accepted: 02 November 2020 Published: 01 December 2020

Citation: Abu-Farha M, Al-Mulla F, Thanaraj TA, Kavalakatt S, Ali H, Abdul Ghani M and Abubaker J (2020) Impact of Diabetes in Patients Diagnosed With COVID-19.

Front. Immunol. 11:576818 doi: 10.3389/fimmu.2020.576818
Abbreviations: SARS-CoV-2, severe acute respiratory syndrome coronavirus-2; ARDS, acute respiratory distress syndrome; $\mathrm{DM}$, diabetes mellitus; MERS-CoV, middle east respiratory syndrome coronavirus; $\mathrm{COPD}$, chronic obstructive pulmonary disease; CVD, cardiovascular disease; CKD, chronic kidney disease; ACE2, angiotensin-converting enzyme 2; T2DM, type-2 $\mathrm{dm}$; TNF- $\alpha$, tumor necrosis factor alpha; MCP-1, monocyte chemoattractant protein-1; IL-6, interleukin-6; rhACE2, recombinant angiotensin-converting enzyme 2; TCZ, tocilizumab; IFITM, interferon-induced transmembrane; ADAM17, a disintegrin and metallopeptidase domain 17; GRP78, glucose regulated protein 78; SBD $\beta$, GRP78 substrate binding domain; BDKA, Diabetic Ketoacidosis; DPP-4i, Dipeptidyl peptidase 4 inhibitor; AICAR, 5-Aminoimidazole-4carboxamide ribonucleotide. 


\section{WORSE OUTCOMES IN COVID-19 PATIENTS AFFECTED BY OBESITY AND DIABETES}

COVID-19 is caused by the coronavirus SARS-CoV-2 and has emerged as a fast-spreading contagious disease affecting most countries across the globe (1). SARS-CoV-2 is the third coronavirus appearance in human history following severe acute respiratory syndrome coronavirus (SARS-CoV) and the Middle East respiratory syndrome coronavirus (MERS-CoV) $(2,3)$. Coronaviruses are a family of enveloped viruses encoded by a single-stranded positive-sense RNA genome and named for the crown-like appearance of their virions under the electron microscope. The key feature of SARS-CoV-2 that differentiates it from other viruses is its transmissibility combined with a greater risk of mortality due to the acute respiratory distress syndrome (ARDS). Signs and symptoms of SARS-CoV-2 infections range from mild/ asymptomatic infections (20-86\% of all infections), restricted to the upper respiratory tract (20-86\% of all infections), to severe respiratory distress characterized by the spread of infection to the lower airways leading to regional inflammation and pneumonia. This is manifested particularly in patients with comorbidities such as chronic obstructive pulmonary disease (COPD), asthma, diabetes, hypertension, and cardiovascular disease (CVD) $(4,5)$.
Significantly, Maddaloni et al. suggested an increased prevalence of COPD and of chronic kidney disease (CKD) in Covid-19 patients with diabetes (6).

People with diabetes mellitus (DM), severe obesity, CVD, and hypertension are at a higher risk of poor outcome from COVID19 (4, 7-10). The reasons underlying this increased risk have not been determined. However, a panoply of factors may contribute to type-2 DM (T2DM) patient increased risk of poor outcomes of COVID-19 disease (Figure 1). Individuals affected by diabetes and/or obesity generally have an impaired innate and adaptive immune response, characterized by a state of chronic low-grade inflammation (11), which can lead to abrupt systemic metabolic alteration, characterized by higher levels of leptin (a proinflammatory adipokine) and lower adiponectin (an antiinflammatory adipokine) (12-16). An unfavorable hormone environment also contributes to dysregulation of the immune response (17). Typically, obese people have defective innate immunity manifested by enhanced production of several proinflammatory cytokines, such as tumor necrosis factor alpha (TNF- $\alpha$ ), monocyte chemoattractant protein-1 (MCP-1), and interleukin-6 (IL-6) (18). Upon antigen exposure, obesityrelated chronic inflammation reduces the activation of macrophages and dampens proinflammatory cytokine production (19). This exceptional obesogenic state may partly

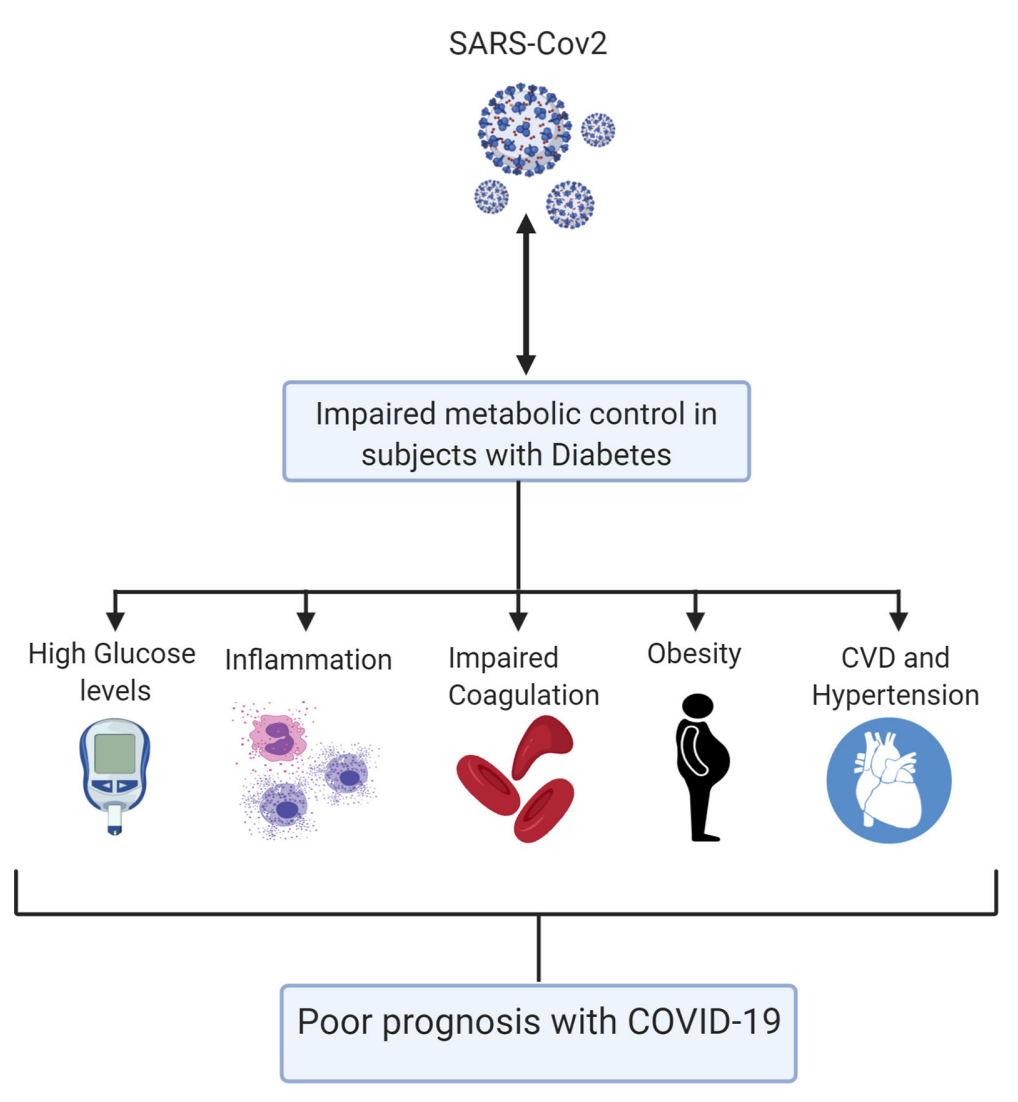

FIGURE 1 | A schematic model summarizing the various mechanisms by which diabetes can impact on COVID-19 poor outcome. 
explain the presence of antiviral-resistance and vaccine-escape deviations in the obese population $(19,20)$. Moreover, B- and Tcell responses are weakened in obese patients and even more so in obese patients with diabetes (21). After analyzing a case cohort of 70,000 individuals infected with COVID-19, the Chinese Centre for Disease Control and Prevention reported augmented mortality in individuals with diabetes, increasing from $2.3 \%$ in the general population to $7.3 \%$ in people with diabetes (22). Interestingly, earlier studies demonstrated that individuals with diabetes exhibit a similar high risk for SARS and MERS $(23,24)$. Among patients infected with the SARS virus, it has been shown that histories of diabetes and hyperglycemia are independent predictors of mortality and morbidity and that metabolic control might improve their prognosis (24). Moreover, hyperglycemia is a strong prognostic predictor of outcome in hospitalized patients with COVID-19. Earlier studies showed that hyperglycemic patients with COVID19 displayed higher cumulative incidence of severe disease than normoglycemic controls $(25,26)$. Possible mechanisms for this increased mortality include hyperglycemia-induced changes in the immune system and increases in inflammatory cytokines (27). Furthermore, among elderly individuals who were at higher risk of death from COVID-19, 26.8\% had diabetes (4). In the United States, $10.5 \%$ of the total population has diabetes (4). Similarly, obese individuals are at higher risk of developing complications from SARS-CoV-2 $(28,29)$.

In this review, we will discuss current and growing perceptions pertinent to the metabolic impact of coronavirus infections while paying special attention to the main pathways and mechanisms that are connected to the pathophysiology and treatment of diabetes.

Hypertension is another predictor of poor outcomes in COVID-19 patients. This may be due to the SARS-CoV-2 binding to the angiotensin-converting enzyme 2 (ACE2) in human epithelial lung cells, potentially involved in ARDS. Ace2 KO mice display severe pathology of ARDS (30). An earlier report has shown that recombinant angiotensinconverting enzyme 2 (rhACE2) can attenuate arterial hypoxemia and pulmonary blood flow in a piglet model of lipopolysaccharide-induced ARDS (31). ACE2 exerts its functions through cleaving either Angiotensin I or Angiotensin II into inactive Angiotensin (1-9) and Angiotensin (1-7) respectively. Angiotensin (1-9) gets further metabolized into Angiotensin (1-7). Angiotensin (1-7) is a vasodilator. Hence, ACE2 counteracts the vasoconstrictor effects of the ACEAngiotensin II axis. Angiotensin-converting enzyme inhibitors (ACEi) and/or angiotensin receptor blockers (ARBs) may interfere with angiotensin-converting enzyme 2 expression and/or activity. Thus, as recommended by several medical associations, and in light of more scientific evidence supporting their beneficial/non-harmful impact, ACEis/ARBs should be continued in COVID-19 patients (32-34). Moreover, the impact of metabolic syndrome (MS) and its comorbidities on COVID-19 prognosis must be considered. Yet, MS by definition is a set of metabolic disorders that include insulin resistance, dyslipidemia, central obesity and hypertension. All are risk factors for the development of type-2 diabetes and cardiovascular diseases (35). In 2017, it was estimated that MS affected $20 \%$ of North American population, 25\% of European population and approximately $15 \%$ of Chinese population (36). Considering the presence of MS across different ethnicities and continents, more future studies focusing on the effect of MS on COVID-19 outcomes are needed.

Studies from different countries have demonstrated a varying prevalence of diabetes, other comorbidities, and mortality among patients infected with COVID-19. Table 1 summarizes the

TABLE 1 | Prevalence (\%) of comorbidities in COVID-19 infected patients.

\begin{tabular}{|c|c|c|c|c|c|c|}
\hline Study & Sample size (n) & Diabetes (\%) & CVD (\%) & HTN (\%) & CKD (\%) & Ref \\
\hline Covid-19 group, Italy & 481 & 33.9 & 30.1 & 73.8 & 20.2 & (37) \\
\hline Zhou et al. & 191 & 19 & 8 & 30 & 1 & (8) \\
\hline Wu C et al. & 201 & 10.9 & 4 & 19.4 & 1 & (9) \\
\hline Guan et al. & 1,099 & 7.4 & 3.8 & 15 & 0.7 & (10) \\
\hline Bhatraju et al. & 24 & 58 & $N R$ & $N R$ & 21 & (38) \\
\hline Liu J et al. & 61 & 8.2 & 1.6 & 19.7 & $N R$ & (41) \\
\hline Guo et al. & 187 & 15 & 11.2 & 32.6 & 3.2 & (42) \\
\hline Huang et al. & 41 & 19.5 & 15 & 14.6 & $N R$ & (43) \\
\hline Chen $\mathrm{N}$ et al. & 99 & 12.1 & 40 & $N R$ & NR & (44) \\
\hline Wang et al. & 138 & 10.1 & 19.6 & 31.2 & 2.9 & (45) \\
\hline Yang J et al. & Meta-analysis of eight studies $n=46,248$ & 0.08 & 0.05 & 0.17 & NR & (46) \\
\hline Singh et al. & Meta-analysis of 10 studies = 2,209 & 0.11 & 0.07 & 0.21 & NR & $(50)$ \\
\hline Hu Y et al. & Meta-analysis of 21 studies $n=47,344$ & 7.7 & 4.7 & 15.6 & 2.1 & (37) \\
\hline
\end{tabular}

CVD, cardiovascular disease; HTN, hypertension; CKD, chronic kidney disease; NR, not reported; CDC, Centers for Disease Control and Prevention. 
TABLE 2 | Prevalence of diabetes amongst non-severe and severe COVID-19 infected patients.

\begin{tabular}{lccccc}
\hline Study & $\begin{array}{c}\text { Sample } \\
\text { size(n) }\end{array}$ & DM (\%) & $\begin{array}{c}\text { ICU } \\
\text { admission } \\
\text { (Severe/ } \\
\text { Critical) } \\
\text { (\%)* }\end{array}$ & $\begin{array}{c}\text { Significance } \\
\text { p value of } \\
\text { non-severe vs } \\
\text { severe CovID }\end{array}$ & Ref. \\
\hline Wu et al. & 201 & $10.90 \%$ & $19.00 \%$ & 0.002 & $(9)$ \\
Guan et al. & 1,099 & $7.40 \%$ & $16.20 \%$ & NR & $(10)$ \\
CDC, USA & 7,162 & $10.90 \%$ & $32.00 \%$ & NR & $(39)$ \\
Zhang et al. & 140 & $12.10 \%$ & $13.80 \%$ & 0.615 & $(40)$ \\
Huang et al. & 41 & $15 \%$ & $25.00 \%$ & 0.160 & $(43)$ \\
Wang et al. & 138 & $10.10 \%$ & $22.20 \%$ & 0.009 & $(45)$ \\
Liu J et al. & 61 & $8.20 \%$ & $17.60 \%$ & 0.094 & $(41)$ \\
Hu Y et al. & Meta-analysis & $7.70 \%$ & $44.50 \%$ & NR & $(37)$ \\
& of 21 studies & & & & \\
& $\mathrm{n}=47,344$ & & & & \\
\hline
\end{tabular}

DM, diabetes mellitus; Ref., references; CDC, Centers for Disease Control and Prevention. *\% is calculated from total population with COVID-19.

prevalence of comorbidities among patients with COVID-19, and Tables 2 and 3 summarize the prevalence of diabetes and other comorbidities among patients with severe versus mild COVID-19 symptoms and among survivors versus nonsurvivors of COVID-19. Overall, it was reported that the proportion of people affected by diabetes among COVID-19 patients was from $5.3 \%$ to $20 \%$. Although the COVID-19 surveillance group in Italy showed a higher prevalence of comorbidities such as hypertension and diabetes $(73 \%$ and $34 \%$, respectively), other studies from China showed a 9 to $15 \%$ prevalence rate. Bhatraju et al. (38). reported that US patients had morbidity rates similar to patients in Italy. However, it is important to note that Bhatraju et al. included only critically ill patients from the Seattle area. Differences in the characteristics of patients included in the studies could explain the difference in the prevalence of comorbidities among various cohorts. Data also show that the presence of diabetes is associated with a high risk of severe to critical illness in 14 to $32 \%$ of patients with COVID-19 $(39,40)$. Other studies showed higher rate of admission into the intensive care unit (ICU) among people who were diagnosed with diabetes or other comorbidities when compared with non-ICU patients $(22.2 \mathrm{vs}$ 5.9\%) (45). Furthermore, mortality rates among COVID-19 patients with various comorbidities when compared to those without any comorbidities were 15 vs $2.3 \%$, respectively (43-45). Notably, several studies showed that diabetes is strongly associated with increased risk of mortality due to COVID-19 as compared with COVID-19 patients without diabetes and other comorbidities (22-31 vs 2-4\%) (8, 10, 47). Zhou et al. also showed that the mortality rate among COVID-19 patients with diabetes was higher than the overall mortality rate with the viral infection (8). Wu et al. showed that diabetes was associated with a hazard ratio of 2.3 for ARDS (9). Other studies associated diabetes to the severity of COVID-19 (51). Hence, it was proposed that the course of treatment and prognosis should be stratified based on occurrence or absence of comorbidities (52).

In Italy, patients with diabetes showed high prevalence, severity of disease and mortality during SARS-COV-2 infection as well as higher rates of ICU admission. They frequently reported respiratory symptoms and were at increased risk of numerous pulmonary diseases, such as COPD, bronchial severe asthma and idiopathic pulmonary fibrosis $(53,54)$. Thus, we speculate that the complicated alveolar-capillary network of lungs could be targeted by diabetes micro-vascular injury. Recently, continuous experimental therapy with monoclonal antibody against the IL- 6 receptor (tocilizumab, TCZ) in Italy seems to have positive effects on severe lung disease and prognosis in patients with COVID-19. Hence, TCZ could be administered to patients with diabetes during the SARS-COV-2 infection (55). However, an earlier study showed that at admission, hyperglycemic $(\mathrm{n}=31)$ vs. normoglycemic $(\mathrm{n}=47)$ patients had fivefold higher IL-6 levels, which persisted even after TCZ administration $(\mathrm{P}<0.05)(56)$. Interestingly, in a riskadjusted Cox regression analysis, TCZ in hyperglycemic patients failed to reduce risk of severe outcomes as it did in normoglycemic patients $(\mathrm{P}<0.009)$. Thus, hyperglycemia could result in an unfavorable effect on hospital admission, clinical outcomes and drug therapy $(25,26,56)$. It is possible that comorbidities associated with diabetes (e.g., obesity, hypertension, and CVD) contribute to increased morbidity and mortality due to COVID-19. Diabetes was associated with COVID-19 poor outcomes (51) and with increased time required for viral clearance (4). Increased expression of ACE2, furin, and IL-6 and impaired T-cell function are several factors that were associated with the risk and severity of SARS-CoV2 infection in individuals with diabetes (57).

COVID-19 could cause endothelial dysfunction and a hypercoagulation state. This condition is intensified by hypoxia, which augments thrombosis by both increasing blood viscosity and hypoxia-inducible transcription factors (HIF) $(58,59)$. Consequently, these could lead to pulmonary embolism with occlusion and micro-thrombosis in pulmonary vessels, as detected in critically ill COVID-19 patients (59). It is also

TABLE 3 | Prevalence of diabetes among non-survivor and survivor COVID-19 infected patients.

\begin{tabular}{|c|c|c|c|c|c|c|}
\hline Study & Sample size (n) & DM in entire cohort (\%) & DM (\%) in non-survivors & DM (\%) in survivors & Mortality rate & Ref. \\
\hline Zhou et al. & 191 & $19 \%$ & $31.00 \%$ & $14.00 \%$ & OR $2.8(1.35$ to 6.05$) p<0.001$ & (8) \\
\hline Wu et al. & 88 & $18.2 \%$ & $25.00 \%$ & $12.50 \%$ & HR $1.58(0.80$ to 3.13$), p=0.19$ & (22) \\
\hline Guan et al. & 1,099 & $7.4 \%$ & $26.90 \%$ & $6.10 \%$ & $N R$ & (10) \\
\hline Yang $X$ et al. & 52 & $17 \%$ & $22 \%$ & $10 \%$ & NR & $(47)$ \\
\hline Chen $\mathrm{N}$ et al. & 274 & $17 \%$ & $21.00 \%$ & $14.00 \%$ & NR & (44) \\
\hline
\end{tabular}


reported that COVID-19 is associated with increased incidence of coagulation as well as thrombotic and inflammatory events (60), which was responsible, at least in part, for the severe morbidity and mortality. This suggests that COVID-19 activates yet another unidentified mechanism, which is involved in the coagulation process. Interestingly, it is well established that diabetes is a state of increased coagulability; where increased plasminogen activator inhibitor-1 is a consistent finding in patients with diabetes. Thus, increased coagulability in diabetes may be a possible mechanism that links diabetes to severity of COVID-19.

\section{POSSIBLE MECHANISMS THAT PREDISPOSE COVID-19 PATIENTS WITH DIABETES AND/OR OBESITY TO POOR OUTCOMES}

Considering the high incidence of obesity, hypertension, and CVD in patients with diabetes, it remains unclear whether diabetes is an independent contributor to the higher morbidity and mortality associated with COVID-19 (7-10). Maddaloni et al. have shown that patients with cardiometabolic multimorbidity, and not diabetes or CVD alone, experience worse COVID-19 outcomes (61). Nevertheless, plasma glucose levels and diabetes are independent predictors of mortality and morbidity in patients with SARS $(24,62)$. Mechanisms that likely increase the vulnerability for COVID-19 in DM patients comprise increased binding affinity and efficient virus entry, reduced viral clearance, weakened $\mathrm{T}$-cell role, increased susceptibility to cytokine storm disorder, and the existence of CVD. Lung cells, including pneumocytes, are the main cellular sites for coronavirus entrance and inflammation (63). They express key proteins that enable coronavirus entry into cells, such as ACE2, transmembrane protease serine 2 (TMPRSS2), furin, and dipeptidyl peptidase-4 (DPP4). ACE2 and DPP4 also have established multiple metabolic activities linked to the pharmacologic and physiologic control of cardiovascular and glucose homeostasis and DPP4 inhibitors are used extensively in diabetes therapy (28).

Increased ACE2 expression in pulmonary cells, kidney, myocardium, and pancreas may mediate increased cellular binding of SARS-CoV-2 (64-66). The increased expression of ACE2 in these tissues is well documented in animal models of diabetes $(67,68)$. Although insulin administration downregulates ACE2 expression $(46,68)$, other hypoglycemic agents such as glucagon-like peptide-1 (GLP-1) agonists and thiazolidinediones (pioglitazone), anti-hypertensive drugs such as statins, and ACE inhibitors increase ACE2 expression (69-73). Recently, Rao et al. investigated illnesses or traits that may be connected to increased ACE2 expression in the lung. Using a phenome-wide Mendelian randomization analyses, they identified the association between diabetes and higher lung ACE2 expression (74). Moreover, circulating levels of furin (cellular protease) were found to be higher in patients with type-2 diabetes (75). The findings of these studies support the hypothesis that COVID-19 patients with diabetes are predisposed to poor outcomes. Furthermore, a recent study stated that clearance of SARS-CoV-2 was delayed in patients with diabetes (76). However, more extensive studies are needed to confirm this finding.

\section{HOW ARE THE DIFFERENT HOST- CELLULAR PROTEINS INVOLVED IN SARS-COV-2 INFECTION ASSOCIATED WITH DIABETES?}

Apart from ACE2, a number of other host-cellular protein components are thought to have the ability to regulate the entry of SARS-COV-2; such components are known to be involved in the pathogenesis of diabetes, as illustrated in Figure 2 and as described below.

\section{ACE2}

ACE2 acts as the receptor for the binding of SARS-CoV-2 with the host cell. It is already known that the binding of the SARS coronavirus to its receptor damages islets and causes acute diabetes (77). Clinical data, which includes patients with mild and severe COVID-19, established the existence of mild pancreatitis (78). Diabetes and hypertension (common comorbidities associated with COVID-19) are often treated with ACE inhibitors and angiotensin II type-I receptor blockers. Studies have reported that the expression of ACE2 is elevated in people with diabetes treated with these medications $(79,80)$. The higher levels of ACE2 can thus facilitate critical illness in COVID-19 patients (81).

\section{Furin}

Furin cleaves cell surface proteins. The SARS-CoV-2 S-protein S1/S2 cleavage site is the target for furin during infection. This cleavage is critical, as it allows the fusion sequences on the COVID-19 spike protein to be exposed for the fusion of the virus with the host cell membranes $(1,65,82)$. Thus, high levels of furin enhance the ability of the virus to enter the host cell. It is known that individuals with high plasma furin concentrations have a pronounced dysmetabolic phenotype and elevated risk of diabetes and premature mortality $(75,83)$. A point mutation at the furin cleavage site in the insulin pro-receptor was seen in an individual with extreme insulin-resistant diabetes (84). Furthermore, variations in the furin gene have been associated with decreased triglyceride and increased high-density lipoprotein cholesterol levels (85). Furin has an impact on the pancreas, as verified by previous studies, which demonstrated that furin controls the growth of pancreatic $\beta$-cells (86). It also plays a role in granular acidification in the endocrine pancreas via impaired processing of Ac45 (87). We have previously identified a higher proportion of damaging variations in the furin gene in the Arab population as compared with Europeans (88), which is a population with high rates of diabetes that requires special attention during this pandemic (89). 


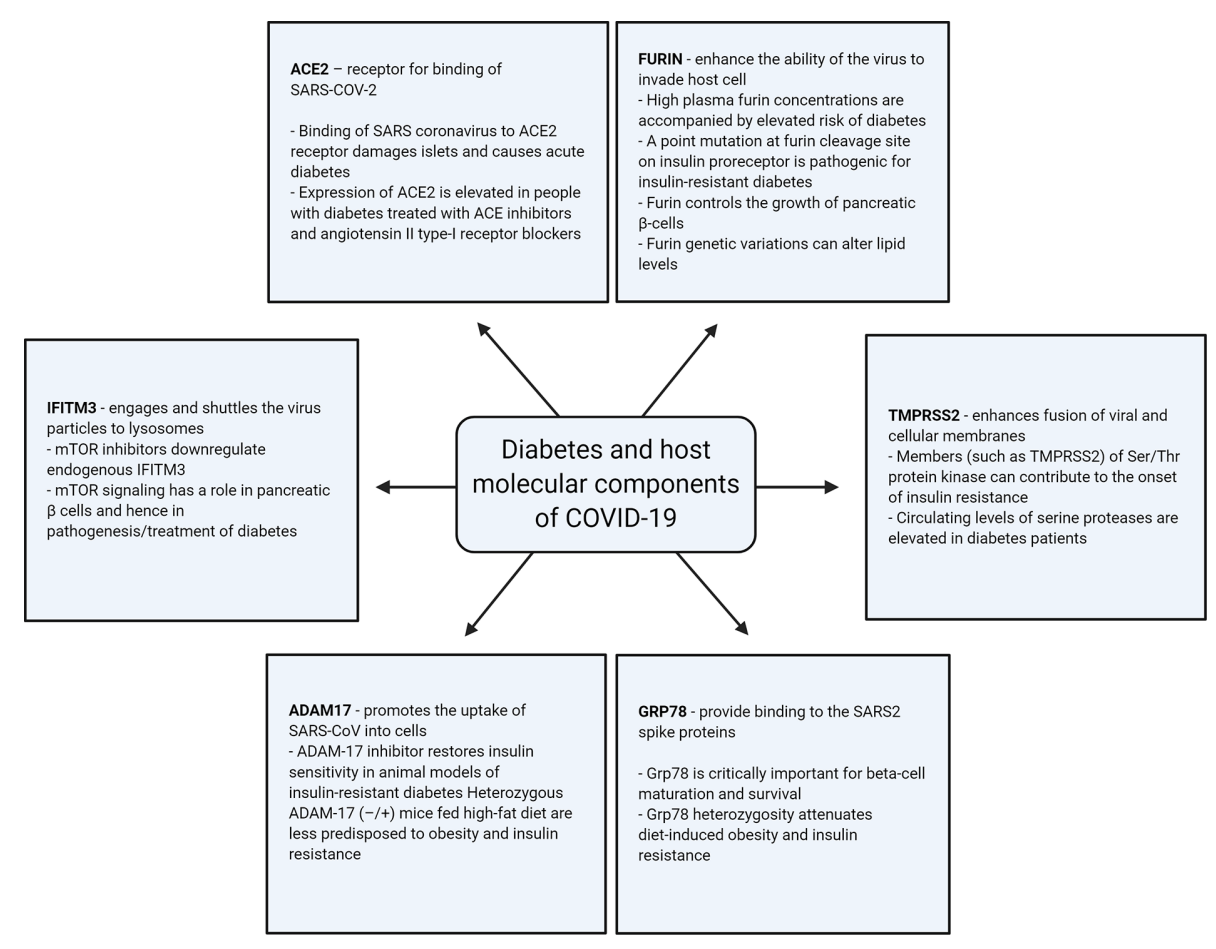

FIGURE 2 | |llustration of association of the different host-cellular proteins involved in SARS-COV-2 infection with diabetes.

\section{TMPRSS2}

SARS-CoV-2 uses the SARS-CoV receptor ACE2 for entry, and the serine protease TMPRSS2 is required for S-protein priming, which entails S-protein cleavage at the S1/S2 and the S2' site and allows fusion of viral and cellular membranes. TMPRSS2 belongs to the family of serine proteases. It is now known that ser/thr protein kinases contribute to the onset of insulin resistance via the introduction of phosphorylation-based negative feedback control mechanisms, which disengage the insulin receptor from its downstream effectors (90). Circulating levels of serine proteases, such as granzyme B, are elevated in diabetes patients (91). Hence, it can be assumed that the increased activity of TMPRSS2 can increase the viral entry in the host.

\section{IFITM3}

Interferon-induced transmembrane (IFITM) proteins are important effectors that inhibit viral infections. IFITM3 directly engages and shuttles the incoming virus particles to lysosomes. It is known that the MERS-CoV entry into host cells is sensitive to inhibition by IFITM proteins (particularly IFITM3) and that the cellular context and/or IFITM expression levels can affect the efficiency of inhibition $(92,93)$. IFITM3 is now indicated as a novel entry site in the SARS-CoV-2 domain as well $(94,95)$. Inhibitors of the mammalian target of rapamycin (mTOR), such as rapamycin, downregulate endogenous IFITM3 through a lysosomal degradation pathway in hematopoietic and non-hematopoietic cells (96). Interestingly, mTOR signaling has a role in pancreatic $\beta$ cells and immune cells, and hence it is also involved in the pathogenesis and treatment of diabetes (97).

\section{Adam17}

In the context of SARS-CoV infection, it has been proposed that SARS-S binding to ACE2 triggers shedding of ACE2 via the disintegrin and metallopeptidase domain 17 (ADAM17) protein to release the extracellular domain of ACE2 into the extracellular space. This process promotes the uptake of SARS-CoV into cells $(98,99)$. It is now further proposed that the inhibition of ADAM17 may exert a protective effect on COVID-19 (100). ADAM17 is a metalloprotease and disintegrin that lodges in the plasma membrane in several cell types and can cleave a wide variety of cell surface proteins. In this way, ADAM17 can influence several physiological and pathological processes (101). In animal models of insulin-resistant diabetes, the intraperitoneal injection of ADAM-17 inhibitor, restored insulin sensitivity through the inhibition of TNF- $\alpha$ (102). Consistent with these findings, Serino et al. demonstrated that heterozygous ADAM-17 (-/+) mice fed a high-fat diet were less predisposed to obesity and insulin resistance than their wild-type littermates (103).

\section{Other Players: GRP78 and CD147}

It appears that apart from the ACE2 receptor entry mode, SARSCoV-2 may use the protease called TMPRSS2 to enter the cells; some researchers speculate that there can be at least 8 other different proteases. It is also proposed that other receptors such as glucose regulated protein 78 (GRP78 receptors) may provide 
binding to the SARS-CoV-2 spike proteins. Protein-protein docking studies revealed that four regions of the spike protein can fit tightly in the GRP78 substrate binding domain $\beta$ (SBD $\beta$ ) (104). Grp78 is critically important for $\beta$-cell maturation and survival; it is demonstrated that Grp78 heterozygosity attenuates diet-induced obesity and insulin resistance (105). It is also possible that other receptors mediate the entry of SARS-CoV2, such as CD147 into T cells. Also called Basigin or EMMPRIN, CD147 is a transmembrane glycoprotein that belongs to the immunoglobulin superfamily on the surface of T lymphocytes (106). A recent study reported that it is a novel invasive route for SARS-CoV-2 entry (106, 107). CD147 is essential for diabetesassociated recombinant tissue-plasminogen activator (rt-PA)induced hemorrhagic transformation, and reduced CD147 glycosylation is an encouraging therapy for neurovascular-unit repair following rt-PA treatment of diabetes patients (108).

\section{USE OF GLUCOSE-LOWERING THERAPIES IN COVID-19 PATIENTS WITH DIABETES}

Lack of specific and effective therapeutics is the major challenge in dealing with COVID-19 patients that are suffering from severe comorbidities such as diabetes. In the absence of specific medication for COVID-19 patients, it is essential to evaluate the applicability of drugs in practice for various comorbidities. Diabetes is one of the major comorbidities of COVID-19 patients who developed ARDS (43). It was originally thought that some anti-diabetes treatment (such as metformin, PPARs, DPP4 inhibitors, GLP-1R agonists, SGLT2 inhibitors and insulin therapy) could influence the course of COVID-19; however, no convincing evidence has emerged to support this view.

\section{GLP-1R Agonists}

GLP-1R agonists target many anti-inflammatory pathways in animals and lessen systemic inflammation in individuals affected by diabetes and obesity (109). These drugs decrease pulmonary type- 2 immune cytokine reactions and the degree of lung injury in mice after respiratory viral infection (110). Thus, GLP-1-based drugs possess strong anti-inflammatory effects in lungs and could become possible repurposed drugs, useful to treat COVID-19 patients with ARDS (111). However, the beneficial effects of these drugs remain to be convincingly established in COVID-19.

\section{SGLT2 Inhibitors}

Based on the findings that showed the organ-protective effects of SGLT-2 inhibitors (112), in addition to their glycemic benefits, these drugs were proposed to provide benefits in COVID-19 settings. However, these inhibitors were also known to lead to risk of dehydration and euglycemic Diabetic Ketoacidosis (DKA) (112). Though SGLT2 inhibitors may be potentially beneficial as organ protective agents in COVID-19, there is no completed clinical trial to assess the risk/benefit balance of using these inhibitors in COVID-19 patients. Thus, caution needs to be exercised when these inhibitors are used (113). It is advisable to re-evaluate or discontinue SGLT2 inhibitors upon hospital admission of unstable patients with severe SARS-CoV2 infection.

\section{Insulin Therapy}

Given that insulin therapy has an optimal glucose-lowering effect in patients affected by diabetes, it is suggested that insulin is the treatment of choice in hospitalized COVID-19 patients with diabetes $(114,115)$. As stated in the American Diabetes Association guidelines, basal insulin or a basal plus bolus correction insulin regimen is the favorite treatment for noncritically ill hospitalized patients. Continuous intravenous insulin infusion is preferred in critically ill patients. A target glucose range of $7.8-10.0 \mathrm{mmol} / \mathrm{L}$ is recommended for both critically and noncritically ill patients (114). Moreover, a recent study examined the effects of optimal glycemic control using insulin therapy in patients with hyperglycemia affected by COVID-19 (25). Fifty-nine patients with COVID-19 hospitalized with moderate disease were stratified into hyperglycemic and normoglycemic groups based on glycemia measure of $>7.77 \mathrm{mmol} / \mathrm{L}$ at the time of hospital admission. Their data showed that patients with hyperglycemia treated with insulin infusion had a lower risk of severe disease outcome than patients without insulin infusion. Accordingly, insulin infusion may be an effective method for reaching glycemic control and improving outcomes in patients with COVID-19 (25). Consistently, Bornstein et al. recommended insulin treatment for diabetic patients with severe COVID-19 (116). However, a recent study examining the effects of insulin therapy in hospitalized diabetic patients with COVID-19 reported a greater than threefold risk of mortality and severe outcome in treated patients (117). Thus, it remains unclear whether insulin therapy worsens COVID-19 outcomes or if these results were caused by a patient selection bias (note: patients with diabetes receiving insulin tend to have longer duration of disease with a higher rate of comorbidities).

\section{ACE2 and DPP4}

DPP4 (CD26), a transmembrane ectopeptidase, acts as a coreceptor for a subset of coronaviruses including MERS-CoV. Its activity can potentially modulate the levels and activity of many immunomodulatory cytokines and chemokines (118). Although ACE2 and DPP4 are crucial modulators of glucose homeostasis, there is no convincing evidence to propose that medications regulating the ACE2- or DPP4-linked pathways yield obvious benefit or harm during coronavirus infections. Several studies have evaluated whether DPP4i are associated to improved Covid-19 outcomes, with apparently opposing results. Some groups have shown that patients with COVID-19 who were on Dipeptidyl peptidase 4 inhibitor (DPP-4is) had a similar disease outcome as those who were not (119-121). Instead, Solerte et al. have found that sitagliptin (DPP-4i) treatment at the time of admission was associated with improved clinical outcomes and reduced mortality, compared to standard-of-care treatment (122). ACE2 decoy receptors or antibodies targeting ACE2 can be promising tools to block the viral cell-entry. However, the 
impact of these drugs on metabolic parameters has not been sensibly investigated and requires further investigation (123).

\section{CONCLUSION}

Evidence implies that obesity and diabetes are leading risk factors that affect the severity of disease caused by coronaviruses infections, such as COVID-19. Among patients infected with the SARS-CoV-2, history has shown that diabetes and hyperglycemia are independent predictors for mortality and morbidity, and that glycemic control might improve patient prognosis. The risk seen among people with diabetes may be due to insulin resistance, inflammation, or hypercoagulation, or owed to underlying obesity, which may lead to adverse outcome.

Several classes of anti-obesity and anti-diabetes medications (such as metformin, 5-Aminoimidazole-4-carboxamide ribonucleotide (AICAR), and $\operatorname{PPAR} \gamma$ agonists) are known to modulate the immune system and result in improved insulin sensitivity. Hence, further investigations are warranted to

\section{REFERENCES}

1. Walls AC, Park YJ, Tortorici MA, Wall A, Mcguire AT, Veesler D. Structure, Function, and Antigenicity of the SARS-CoV-2 Spike Glycoprotein. Cell (2020) 181(2):281-292.e6. doi: 10.1016/j.cell.2020.02.058

2. Zhou J, Chu H, Chan JF, Yuen KY. Middle East respiratory syndrome coronavirus infection: virus-host cell interactions and implications on pathogenesis. Virol J (2015) 12:218. doi: 10.1186/s12985-015-0446-6

3. Chan JF, Lau SK, To KK, Cheng VC, Woo PC, Yuen KY. Middle East respiratory syndrome coronavirus: another zoonotic betacoronavirus causing SARS-like disease. Clin Microbiol Rev (2015) 28(2):465-522. doi: 10.1128/CMR.00102-14

4. Muniyappa R, Gubbi S. COVID-19 pandemic, coronaviruses, and diabetes mellitus. Am J Physiol Endocrinol Metab (2020) 318(5):E736-e741. doi: 10.1152/ajpendo.00124.2020

5. Li B, Yang J, Zhao F, Zhi L, Wang X, Liu L, et al. Prevalence and impact of cardiovascular metabolic diseases on COVID-19 in China. Clin Res Cardiol (2020) 109(5):531-8. doi: 10.1007/s00392-020-01626-9

6. Maddaloni E, D'onofrio L, Alessandri F, Mignogna C, Leto G, Pascarella, et al. Clinical features of patients with type 2 diabetes with and without Covid-19: a case control study (CoViDiab I). Diabetes Res Clin Pract (2020) p:108454. doi: 10.1016/j.diabres.2020.108454

7. Onder G, Rezza G, Brusaferro S. Case-Fatality Rate and Characteristics of Patients Dying in Relation to COVID-19 in Italy. JAMA (2020) 323 (18):1775-6. doi: 10.1001/jama.2020.4683

8. Zhou F, Yu T, Du R, Fan G, Liu Y, Liu Z, et al. Clinical course and risk factors for mortality of adult inpatients with COVID-19 in Wuhan, China: a retrospective cohort study. Lancet (2020) 395(10229):1054-62. doi: 10.1016/ S0140-6736(20)30566-3

9. Wu C, Chen X, Cai Y, Xia J, Zhou X, Xu S, et al. Risk Factors Associated With Acute Respiratory Distress Syndrome and Death in Patients With Coronavirus Disease 2019 Pneumonia in Wuhan, China. JAMA Intern Med (2020) 180(7):934-43. doi: 10.1001/jamainternmed.2020.0994

10. Guan WJ, Ni ZY, Hu Y, Liang WH, Ou. Clinical Characteristics of Coronavirus Disease 2019 in China. N Engl J Med (2020) 382(18):170820. doi: 10.1056/NEJMoa2002032

11. Andersen CJ, Murphy KE, Fernandez ML. Impact of Obesity and Metabolic Syndrome on Immunity. Adv Nutr (2016) 7(1):66-75. doi: 10.3945/ an.115.010207

12. Francisco V, Ruiz-Fernández C, Pino J, Mera A, González-Gay MA, Gómez, et al. Adipokines: Linking metabolic syndrome, the immune system, and address their use alone or in combination with other antiviral/ immunomodulatory drugs in the treatment of COVID-19. Moreover, GLP-1R agonists and DPP4 inhibitors are known to mediate anti-inflammatory effects in human patients, while controlling glucose levels in hospitalized patients (124) Nevertheless, there is no convincing evidence advocating the use of these drugs as replacements for insulin in severely ill COVID-19 patients. The fast-growing medical information pertaining to the COVID-19 pandemic entails continuing scrutiny to assess the practical use, risks, and advantages of these anti-hyperglycemic drugs and any other associated medications generally used to treat diabetic people, who are at higher risk of coronavirus infections.

\section{AUTHOR CONTRIBUTIONS}

MA-F, FA-M, TT, SK, HA, MA, and JA contributed to the design, writing, and planning of the manuscript. All authors contributed to the article and approved the submitted version.

arthritic diseases. Biochem Pharmacol (2019) 165:196-206. doi: 10.1016/ j.bcp.2019.03.030

13. Francisco V, Pino J, Campos-Cabaleiro V, Ruiz-Fernández C, Mera A, Gonzalez-Gay MA, et al. Obesity, Fat Mass and Immune System: Role for Leptin. Front Physiol (2018) 9:640. doi: 10.3389/fphys.2018.00640

14. Andrade-Oliveira V, Câmara NO. Adipokines as drug targets in diabetes and underlying disturbances. J Diabetes Res (2015) 2015:681612. doi: 10.1155/ 2015/681612

15. Bremer AA, Jialal I. Adipose tissue dysfunction in nascent metabolic syndrome. J Obes (2013) 2013:393192. doi: 10.1155/2013/393192

16. Faber DR, de Groot PG, Visseren FL. Role of adipose tissue in haemostasis, coagulation and fibrinolysis. Obes Rev (2009) 10(5):554-63. doi: 10.1111/ j.1467-789X.2009.00593.x

17. Ouchi N, Parker JL, Lugus JJ, Walsh K. Adipokines in inflammation and metabolic disease. Nat Rev Immunol (2011) 11(2):85-97. doi: 10.1038/ nri2921

18. Richard C, Wadowski M, Goruk S, Cameron L, Sharma AM, Field CJ. Individuals with obesity and type 2 diabetes have additional immune dysfunction compared with obese individuals who are metabolically healthy. BMJ Open Diabetes Res Care (2017) 5(1):e000379. doi: 10.1136/ bmjdrc-2016-000379

19. Luzi L, Radaelli MG. Influenza and obesity: its odd relationship and the lessons for COVID-19 pandemic. Acta Diabetol (2020) 57(6):759-64. doi: 10.1007/s00592-020-01522-8

20. Karlsson EA, Hertz T, Johnson C, Mehle A, Krammer F, Schultz-Cherry $S$, et al. Obesity Outweighs Protection Conferred by Adjuvanted Influenza Vaccination. mBio (2016) 7(4):e01144-16. doi: 10.1128/ mBio.01144-16

21. Magdy Beshbishy A, Hetta HF. Factors Associated with Increased Morbidity and Mortality of Obese and Overweight COVID-19 Patients. Biol (Basel) (2020) 9(9):280. doi: 10.3390/biology9090280

22. Wu Z, McGoogan JM. Characteristics of and Important Lessons From the Coronavirus Disease 2019 (COVID-19) Outbreak in China: Summary of a Report of 72314 Cases From the Chinese Center for Disease Control and Prevention. Jama (2020) 323(13):1239-42. doi: 10.1001/jama.2020.2648

23. Kulcsar KA, Coleman CM, Beck SE, Frieman MB. Comorbid diabetes results in immune dysregulation and enhanced disease severity following MERSCoV infection. JCI Insight (2019) 4(20):e131774. doi: 10.1172/ jci.insight.131774

24. Yang JK, Zheng Y, Gou X, Pu K, Chen Z, Guo Q, et al. Plasma glucose levels and diabetes are independent predictors for mortality and morbidity in 
patients with SARS. Diabetes Med (2006) 23(6):623-8. doi: 10.1111/j.14645491.2006.01861.x

25. Sardu C, D'onofrio N, Balestrieri ML, Barbieri M, Rizzo MR, Messina V, et al. Outcomes in Patients With Hyperglycemia Affected by COVID-19: Can We Do More on Glycemic Control? Diabetes Care (2020) 43(7):140815. doi: $10.2337 / \mathrm{dc} 20-0723$

26. Sardu C, D'onofrio N, Balestrieri ML, Barbieri M, Rizzo MR, Messina V, et al. Hyperglycaemia on admission to hospital and COVID-19. Diabetologia (2020) 63(11):2486-7. doi: 10.1007/s00125-020-05216-2

27. Schuetz P, Castro P, Shapiro NI. Diabetes and sepsis: preclinical findings and clinical relevance. Diabetes Care (2011) 34(3):771-8. doi: 10.2337/dc10-1185

28. Drucker DJ. Coronavirus Infections and Type 2 Diabetes-Shared Pathways with Therapeutic Implications. Endocr Rev (2020) 41(3):bnaa011. doi: 10.1210/endrev/bnaa011

29. Ryan DH, Ravussin E. COVID 19 and the Patient with Obesity - The Editors Speak Out. Obesity (2020) 28(5):847. doi: 10.1002/oby.22808

30. Imai Y, Kuba K, Rao S, Huan Y, Guo F, Guan B, et al. Angiotensinconverting enzyme 2 protects from severe acute lung failure. Nature (2005) 436(7047):112-6. doi: 10.1038/nature03712

31. Treml B, Neu N, Kleinsasser A, Gritsch C, Finsterwalder T, Geiger R, et al. Recombinant angiotensin-converting enzyme 2 improves pulmonary blood flow and oxygenation in lipopolysaccharide-induced lung injury in piglets. Crit Care Med (2010) 38(2):596-601. doi: 10.1097/CCM.0b013e3181c03009

32. Bosso M, Thanaraj TA, Abu-Farha M, Alanbaei M, Abubaker J, Al-Mulla F. The Two Faces of ACE2: The Role of ACE2 Receptor and Its Polymorphisms in Hypertension and COVID-19. Mol Ther Methods Clin Dev (2020) 18:3217. doi: 10.1016/j.omtm.2020.06.017

33. Vaduganathan M, Vardeny O, Michel T, Mcmurray JJV. ReninAngiotensin-Aldosterone System Inhibitors in Patients with Covid-19. N Engl J Med (2020) 382(17):1653-9. doi: 10.1056/NEJMsr2005760

34. Sardu C, Maggi P, Messina V, Iuliano P, Sardu A, Iovinella V, et al. Could Anti-Hypertensive Drug Therapy Affect the Clinical Prognosis of Hypertensive Patients With COVID-19 Infection? Data From Centers of Southern Italy. J Am Heart Assoc (2020) 9(17):e016948. doi: 10.1161/ JAHA. 120.016948

35. Grundy SM, Cleeman JI, Daniels SR, Donato KA, Eckel RH, Franklin BA, et al. Diagnosis and management of the metabolic syndrome: an American Heart Association/National Heart, Lung, and Blood Institute Scientific Statement. Circulation (2005) 112(17):2735-52. doi: 10.1161/ CIRCULATIONAHA.105.169404

36. Costa FF, Rosário WR, Ribeiro Farias AC, De Souza RG, Duarte GondimRS, Barroso WA. Metabolic syndrome and COVID-19: An update on the associated comorbidities and proposed therapies. Diabetes Metab Syndr (2020) 14(5):809-14. doi: 10.1016/j.dsx.2020.06.016

37. Hu Y, Sun J, Dai Z, Deng H, Li X, Huang Q, et al. Prevalence and severity of corona virus disease 2019 (COVID-19): A systematic review and metaanalysis. J Clin Virol (2020) 127:104371. doi: 10.1016/j.jcv.2020.104371

38. Bhatraju PK, Ghassemieh BJ, Nichols M, Kim R, Jerome, KR, Nalla, et al. Covid-19 in Critically Ill Patients in the Seattle Region - Case Series. N Engl J Med (2020) 382(21):2012-22. doi: 10.1056/NEJMoa2004500

39. CDC Covid-19 response team. Preliminary Estimates of the Prevalence of Selected Underlying Health Conditions Among Patients with Coronavirus Disease 2019 - United States, February 12-March 28, 2020. MMWR Morb Mortal Wkly Rep (2020) 69(13):382-6. doi: 10.15585/mmwr.mm6913e2

40. Zhang JJ, Dong X, Cao YY, Yuan YD, Yang YB, Yan YQ, et al. Clinical characteristics of 140 patients infected with SARS-CoV-2 in Wuhan, China. Allergy (2020) 75(7):1730-41. doi: 10.1111/all.14238

41. Liu K, Fang YY, Deng Y, Liu W, Wang MF, Ma JP, et al. Clinical characteristics of novel coronavirus cases in tertiary hospitals in Hubei Province. Chin Med J (Engl) (2020) 133(9):1025-31. doi: 10.1097/ CM9.0000000000000744

42. Guo T, Fan Y, Chen M, Wu X, Zhang L, He T, et al. Cardiovascular Implications of Fatal Outcomes of Patients With Coronavirus Disease 2019 (COVID-19). JAMA Cardiol (2020) 5(7):811-8. doi: 10.1001/ jamacardio.2020.1017

43. Huang C, Wang Y, Li X, Ren L, Zhao J, Hu Y, et al. Clinical features of patients infected with 2019 novel coronavirus in Wuhan, China. Lancet (2020) 395(10223):497-506. doi: 10.1016/S0140-6736(20)30183-5
44. Chen N, Zhou M, Dong X, Qu J, Gong F, Han Y, et al. Epidemiological and clinical characteristics of 99 cases of 2019 novel coronavirus pneumonia in Wuhan, China: a descriptive study. Lancet (2020) 395(10223):507-13. doi: 10.1016/S0140-6736(20)30211-7

45. Wang D, Hu B, Hu C, Zhu F, Liu X, Zhang J, et al. Clinical Characteristics of 138 Hospitalized Patients With 2019 Novel Coronavirus-Infected Pneumonia in Wuhan, China. Jama (2020) 323(11):1061-9. doi: 10.1001/jama.2020.1585

46. Yang J, Zheng Y, Gou X, Pu K, Chen Z, Guo Q, et al. Prevalence of comorbidities and its effects in patients infected with SARS-CoV-2: a systematic review and meta-analysis. Int J Infect Dis (2020) 94:91-5. doi: 10.1016/j.ijid.2020.03.017

47. Yang X, Yu Y, Xu J, Shu H, Xia J, Liu H, et al. Clinical course and outcomes of critically ill patients with SARS-CoV-2 pneumonia in Wuhan, China: a single-centered, retrospective, observational study. Lancet Respir Med (2020) 8(5):475-81. doi: 10.1016/S2213-2600(20)30079-5

48. Chen T, Wu D, Chen H, Yan W, Yang D, Chen G, et al. Clinical characteristics of 113 deceased patients with coronavirus disease 2019: retrospective study. BMJ (2020) 368:m1091. doi: 10.1136/bmj.m1091

49. Disease control and prevention. The epidemiological characteristics of an outbreak of 2019 novel coronavirus diseases (COVID-19) in China. Zhonghua Liu Xing Bing Xue Za Zhi (2020) 41(2):145-51. doi: 10.3760/ cma.j.issn.0254-6450.2020.02.003

50. Singh AK, Gupta R, Ghosh A, Misra A. Diabetes in COVID-19: Prevalence, pathophysiology, prognosis and practical considerations. Diabetes Metab Syndr (2020) 14(4):303-10. doi: 10.1016/j.dsx.2020.04.004

51. Ali H, Alshukry A, Bu Abbas M, Ali Y, Alahmad B, Al-Shammari AA, et al. Clinical Characteristics and Outcomes of Diabetic COVID-19 patients in Kuwait. medRxiv (2020) p:2020.08.20.20178525.

52. Wang T, Du Z, Zhu F, Cao Z, An Y, Gao Y, et al. Comorbidities and multiorgan injuries in the treatment of COVID-19. Lancet (2020) 395(10228):e52. doi: 10.1016/S0140-6736(20)30558-4

53. Carsana L, Sonzogni A, Nasr A, Rossi RS, Pellegrinelli A, Zerbi P, et al. Pulmonary post-mortem findings in a series of COVID-19 cases from northern Italy: a two-centre descriptive study. Lancet Infect Dis (2020) 20 (10):1135-40. doi: 10.1016/S1473-3099(20)30434-5

54. Poletti V, Capozzolo A. Respiratory Rehabilitation in the COVID-19 Era. Respiration (2020) 99(6):461-2. doi: 10.1159/000509558

55. Sardu C, Gargiulo G, Esposito G, Paolisso G, Marfella R. Impact of diabetes mellitus on clinical outcomes in patients affected by Covid-19. Cardiovasc Diabetol (2020) 19(1):76. doi: 10.1186/s12933-020-01047-y

56. Marfella R, Paolisso P, Sardu C, Bergamaschi L, D'angelo EC, Barbieri, et al. Negative impact of hyperglycaemia on tocilizumab therapy in Covid-19 patients. Diabetes Metab (2020). 46(5):403-405. doi: 10.1016/ j.diabet.2020.05.005

57. Feng SQ, Chen XD, Xia T, Gan L, Qiu H, Dai MH, et al. Cloning, chromosome mapping and expression characteristics of porcine ANGPTL3 and -4. Cytogenet Genome Res (2006) 114(1):44-9. doi: $10.1159 / 000091927$

58. Gupta N, Zhao YY, Evans CE. The stimulation of thrombosis by hypoxia. Thromb Res (2019) 181:77-83. doi: 10.1016/j.thromres.2019.07.013

59. Sardu C, Gambardella J, Morelli MB, Wang, X, Marfella R, Santulli G. Hypertension, Thrombosis, Kidney Failure, and Diabetes: Is COVID-19 an Endothelial Disease? A Comprehensive Evaluation of Clinical and Basic Evidence. J Clin Med (2020) 9(5):1417. doi: 10.3390/jcm9051417

60. Alshukry A, Ali H, Ali Y, Al-Taweel T, Abu-Farha M, Abubaker J, et al. Clinical characteristics of Coronavirus Disease 2019 (COVID-19) patients in Kuwait. medRxiv (2020) p:2020.06.14.20131045. doi: 10.1101/ 2020.10.11.20210740

61. Maddaloni E, D’onofrio L, Alessandri F, Mignogna C, Leto G, Pascarella G, et al. Cardiometabolic multimorbidity is associated with a worse Covid-19 prognosis than individual cardiometabolic risk factors: a multicentre retrospective study (CoViDiab II). Cardiovasc Diabetol (2020) 19(1):164. doi: 10.1186/s12933-020-01140-2

62. Alahmad B, Al-Shammari AA, Bennakhi A, Al-Mulla F, Ali H. Fasting Blood Glucose and COVID-19 Severity: Nonlinearity Matters. Diabetes Care (2020) dc201941. doi: 10.2337/dc20-1941

63. Hamming I, Timens W, Bulthuis ML, Lely AT, Navis G, Van Goor H. Tissue distribution of ACE2 protein, the functional receptor for SARS coronavirus. 
A first step in understanding SARS pathogenesis. J Pathol (2004) 203 (2):631-7. doi: 10.1002/path.1570

64. Verdecchia P, Cavallini C, Spanevello A, Angeli F. The pivotal link between ACE2 deficiency and SARS-CoV-2 infection. Eur J Intern Med (2020) 76:1420. doi: 10.1016/j.ejim.2020.04.037

65. Lukassen S, Chua RL, Trefzer T, Kahn NC, Schneider MA, Muley T, et al. SARS-CoV-2 receptor ACE2 and TMPRSS2 are primarily expressed in bronchial transient secretory cells. EMBO J (2020) 39(10):e105114. doi: $10.15252 / \mathrm{embj} .20105114$

66. Zou X, Chen K, Zou J, Han P, Hao J, Han Z. Single-cell RNA-seq data analysis on the receptor ACE2 expression reveals the potential risk of different human organs vulnerable to $2019-\mathrm{nCoV}$ infection. Front Med (2020) 14(2):185-92. doi: 10.1007/s11684-020-0754-0

67. Roca-Ho H, Riera M, Palau V, Pascual J, Soler MJ. Characterization of ACE and ACE2 Expression within Different Organs of the NOD Mouse. Int J Mol Sci (2017) 18(3):563. doi: 10.3390/ijms18030563

68. Wysocki J, Ye M, Soler MJ, Gurley SB, Xiao HD, BernsteinKE, et al. ACE and ACE2 activity in diabetic mice. Diabetes (2006) 55(7):2132-9. doi: $10.2337 / \mathrm{db} 06-0033$

69. Romaní-Pérez M, Outeiriño-Iglesias V, Moya CM, Santisteban P, González-Matípas LC, Vigo E, et al. Activation of the GLP-1 Receptor by Liraglutide Increases ACE2 Expression, Reversing Right Ventricle Hypertrophy, and Improving the Production of SP-A and SP-B in the Lungs of Type 1 Diabetes Rats. Endocrinology (2015) 156(10):3559-69. doi: 10.1210/en.2014-1685

70. Tikoo K, Patel G, Kumar S, Karpe PA, Sanghavi M, Malek V, et al. Tissue specific up regulation of ACE2 in rabbit model of atherosclerosis by atorvastatin: role of epigenetic histone modifications. Biochem Pharmacol (2015) 93(3):343-51. doi: 10.1016/j.bcp.2014.11.013

71. Zhang W, Xu YZ, Liu B, Wu R, Yang YY, Xiao XQ, et al. Pioglitazone upregulates angiotensin converting enzyme 2 expression in insulin-sensitive tissues in rats with high-fat diet-induced nonalcoholic steatohepatitis. ScientificWorldJournal (2014) 2014:603409. doi: 10.1155/2014/603409

72. Wösten-van Asperen RM, Lutter R, Specht PA, Moll GN, Van Woensel JB, Van Der Loos, et al. Acute respiratory distress syndrome leads to reduced ratio of ACE/ACE2 activities and is prevented by angiotensin-(1-7) or an angiotensin II receptor antagonist. J Pathol (2011) 225(4):618-27. doi: $10.1002 /$ path. 2987

73. Ferrario CM, Jessup J, Chappell MC, Averill DB, Brosnihan KB, Tallant $\mathrm{EA}$, et al. Effect of angiotensin-converting enzyme inhibition and angiotensin II receptor blockers on cardiac angiotensin-converting enzyme 2. Circulation (2005) 111(20):2605-10. doi: 10.1161/ CIRCULATIONAHA.104.510461

74. Rao S, Lau A, So HC. Exploring Diseases/Traits and Blood Proteins Causally Related to Expression of ACE2, the Putative Receptor of SARS-CoV-2: A Mendelian Randomization Analysis Highlights Tentative Relevance of Diabetes-Related Traits. Diabetes Care (2020) 43(7):1416-26. doi: 10.2337/ dc20-0643

75. Fernandez C, Rysä J, Almgren P, Nilsson J. Plasma levels of the proprotein convertase furin and incidence of diabetes and mortality. J Intern Med (2018) 284(4):377-87. doi: 10.1111/joim.12783

76. Chen X, Hu W, Ling J, Mo P, Zhang Y, Jiang Q, et al. Hypertension and Diabetes Delay the Viral Clearance in COVID-19 Patients. medRxiv (2020) p:2020.03.22.20040774. doi: 10.1101/2020.03.22.20040774

77. Yang JK, Lin SS, Ji XJ, Guo LM. Binding of SARS coronavirus to its receptor damages islets and causes acute diabetes. Acta Diabetol (2010) 47(3):193-9. doi: 10.1007/s00592-009-0109-4

78. Liu F, Long X, Zou W, Fang M, Wu W, Li W, et al. Highly ACE2 Expression in Pancreas May Cause Pancreas Damage After SARS-CoV-2 Infection. medRxiv (2020) p:2020.02.28.20029181. doi: 10.1101/2020.02.28.20029181

79. Wan Y, Shang J, Graham R, Baric RS, Li F. Receptor Recognition by the Novel Coronavirus from Wuhan: an Analysis Based on Decade-Long Structural Studies of SARS Coronavirus. J Virol (2020) 94(7):e00127-20. doi: 10.1128/JVI.00127-20

80. Li XC, Zhang J, Zhuo JL. The vasoprotective axes of the renin-angiotensin system: Physiological relevance and therapeutic implications in cardiovascular, hypertensive and kidney diseases. Pharmacol Res (2017) 125(Pt A):21-38. doi: 10.1016/j.phrs.2017.06.005
81. Fang L, Karakiulakis G, Roth M. Are patients with hypertension and diabetes mellitus at increased risk for COVID-19 infection? Lancet Respir Med (2020) 8(4):e21. doi: 10.1016/S2213-2600(20)30116-8

82. Braun E, Sauter D. Furin-mediated protein processing in infectious diseases and cancer. Clin Transl Immunol (2019) 8(8):e1073. doi: 10.1002/cti2.1073

83. Harlid S, Myte R, Van Guelpen B. The Metabolic Syndrome, Inflammation, and Colorectal Cancer Risk: An Evaluation of Large Panels of Plasma Protein Markers Using Repeated, Prediagnostic Samples. Mediators Inflammation (2017) 2017:4803156. doi: 10.1155/2017/4803156

84. Bravo DA, Gleason JB, Sanchez RI, Roth RA, Fuller RS. Accurate and efficient cleavage of the human insulin proreceptor by the human proprotein-processing protease furin. Characterization and kinetic parameters using the purified, secreted soluble protease expressed by a recombinant baculovirus. J Biol Chem (1994) 269(41):25830-7.

85. Ueyama C, Horibe H, Yamase Y, Fujimaki T, Oguri M, Kato K, et al. Association of FURIN and ZPR1 polymorphisms with metabolic syndrome. BioMed Rep (2015) 3(5):641-7. doi: 10.3892/br.2015.484

86. Kayo T, Sawada Y, Suda M, Konda Y, Izumi T, Tanaka S, et al. Proproteinprocessing endoprotease furin controls growth of pancreatic beta-cells. Diabetes (1997) 46(8):1296-304. doi: 10.2337/diabetes.46.8.1296

87. Louagie E, Taylor NA, Flamez D, Roebroek AJ, Bright NA, Meulemans S, et al. Role of furin in granular acidification in the endocrine pancreas: identification of the V-ATPase subunit Ac45 as a candidate substrate. Proc Natl Acad Sci U S A (2008) 105(34):12319-24. doi: 10.1073/pnas.0800340105

88. Al-Mulla F, Mohammad A, Al Madhoun A, Haddad D, Ali H, Eaaswarkhanth $\mathrm{M}$, et al. A comprehensive germline variant and expression analyses of ACE2, TMPRSS2 and SARS-CoV-2 activator FURIN genes from the Middle East: Combating SARS-CoV-2 with precision medicine. bioRxiv (2020) p:2020.05.16.099176. doi: 10.1101/ 2020.05.16.099176

89. Flint SW, Tahrani AA. COVID-19 and obesity-lack of clarity, guidance, and implications for care. Lancet Diabetes Endocrinol (2020) 8(6):474-5. doi: 10.1016/S2213-8587(20)30156-X

90. Zick Y. Role of Ser/Thr kinases in the uncoupling of insulin signaling. Int $J$ Obes Relat Metab Disord (2003) 27 Suppl 3:S56-60. doi: 10.1038/ sj.ijo. 0802503

91. El Mesallamy HO, Hamdy NM, Mostafa DM, Amin AI. The serine protease granzyme B as an inflammatory marker, in relation to the insulin receptor cleavage in human obesity and type 2 diabetes mellitus. J Interferon Cytokine Res (2014) 34(3):179-86. doi: 10.1089/jir.2013.0059

92. Spence JS, He R, Hoffmann HH, Das T, Thinon E, Rice CM, et al. IFITM3 directly engages and shuttles incoming virus particles to lysosomes. Nat Chem Biol (2019) 15(3):259-68. doi: 10.1038/s41589-018-0213-2

93. Wrensch F, Winkler M, Pöhlmann S. IFITM proteins inhibit entry driven by the MERS-coronavirus spike protein: evidence for cholesterol-independent mechanisms. Viruses (2014) 6(9):3683-98. doi: 10.3390/v6093683

94. Thevarajan I, Nguyen THO, Koutsakos M, Druce J, Caly L, Van De Sandt $\mathrm{CE}$, et al. Breadth of concomitant immune responses prior to patient recovery: a case report of non-severe COVID-19. Nat Med (2020) 26: (4):453-5. doi: 10.1038/s41591-020-0819-2

95. Hoffmann M, Kleine-Weber H, Schroeder S, Krüger N, Herrler T, Erichsen $S$, et al. SARS-CoV-2 Cell Entry Depends on ACE2 and TMPRSS2 and Is Blocked by a Clinically Proven Protease Inhibitor. Cell (2020) 181(2):271280.e8. doi: 10.1016/j.cell.2020.02.052

96. Shi G, Ozog S, Torbett BE, Compton AA. mTOR inhibitors lower an intrinsic barrier to virus infection mediated by IFITM3. Proc Natl Acad Sci U S A (2018) 115: (43):E10069-e10078. doi: 10.1073/pnas.1811892115

97. Tuo Y, Xiang M. mTOR: A double-edged sword for diabetes. J Leukoc Biol (2018) 106(2):385-95. doi: 10.1002/JLB.3MR0317-095RR

98. Haga S, Nagata N, Okamura T, Yamamoto N, Sata T, Yamamoto N, et al. TACE antagonists blocking ACE2 shedding caused by the spike protein of SARS-CoV are candidate antiviral compounds. Antiviral Res (2010) 85 (3):551-5. doi: 10.1016/j.antiviral.2009.12.001

99. Haga S, Yamamoto N, Nakai-Murakami C, Osawa Y, Tokunaga K, Sata T, et al. Modulation of TNF-alpha-converting enzyme by the spike protein of SARS-CoV and ACE2 induces TNF-alpha production and facilitates viral entry. Proc Natl Acad Sci U S A (2008) 105(22):7809-14. doi: 10.1073/ pnas.0711241105 
100. Palau V, Riera M, Soler MJ. ADAM17 inhibition may exert a protective effect on COVID-19. Nephrol Dial Transplant (2020) 35(6):1071-2. doi: 10.1093/ ndt/gfaa093

101. Xu J, Mukerjee S, Silva-Alves CR, Carvalho-Galvão A, Cruz JC, Balarini, et al. A Disintegrin and Metalloprotease 17 in the Cardiovascular and Central Nervous Systems. Front Physiol (2016) 7:469. doi: 10.3389/ fphys.2016.00469

102. Togashi N, Ura N, Higashiura K, Murakami H, Shimamoto K. Effect of TNFalpha-converting enzyme inhibitor on insulin resistance in fructose-fed rats. Hypertension (2002) 39(2 Pt 2):578-80. doi: 10.1161/hy0202.103290

103. Serino M, Menghini R, Fiorentino L, Amoruso R, Mauriello A, Lauro D, et al. Mice heterozygous for tumor necrosis factor-alpha converting enzyme are protected from obesity-induced insulin resistance and diabetes. Diabetes (2007) 56(10):2541-6. doi: 10.2337/db07-0360

104. Ibrahim IM, Abdelmalek DH, Elshahat ME, Elfiky AA. COVID-19 spikehost cell receptor GRP78 binding site prediction. J Infect (2020) 80(5):55462. doi: 10.1016/j.jinf.2020.02.026

105. Ye R, Jung DY, Jun JY, Li J, Luo S, Ko HJ, et al. Grp78 heterozygosity promotes adaptive unfolded protein response and attenuates diet-induced obesity and insulin resistance. Diabetes (2010) 59(1):6-16. doi: 10.2337/db09-0755

106. Koch C, Staffler G, Hüttinger R, Hilgert I, Prager E, Cerný J, et al. T cell activation-associated epitopes of CD147 in regulation of the T cell response, and their definition by antibody affinity and antigen density. Int Immunol (1999) 11(5):777-86. doi: 10.1093/intimm/11.5.777

107. Ulrich H, Pillat MM. CD147 as a Target for COVID-19 Treatment: Suggested Effects of Azithromycin and Stem Cell Engagement. Stem Cell Rev Rep (2020) 16(3):434-40. doi: 10.1007/s12015-020-09976-7

108. Xie Y, Wang Y, Ding H, Guo M, Wang X, Dong Q, et al. Highly glycosylated CD147 promotes hemorrhagic transformation after rt-PA treatment in diabetes: a novel therapeutic target? J Neuroinflammation (2019) 16(1):72. doi: 10.1186/s12974-019-1460-1

109. Drucker DJ. Mechanisms of Action and Therapeutic Application of Glucagon-like Peptide-1. Cell Metab (2018) 27(4):740-56. doi: 10.1016/ j.cmet.2018.03.001

110. Bloodworth MH, Rusznak M, Pfister CC, Zhang J, Bastarache L, Calvillo SA, et al. Glucagon-like peptide 1 receptor signaling attenuates respiratory syncytial virus-induced type 2 responses and immunopathology. J Allergy Clin Immunol (2018) 142(2):683-7.e12. doi: 10.1016/j.jaci.2018.01.053

111. Jin T, Liu M. Letter to the editor: Comment on GLP-1-based drugs and COVID-19 treatment. Acta Pharm Sin B (2020) 10(7):1249-50. doi: 10.1016/ j.apsb.2020.05.006

112. Chatterjee S. SGLT-2 inhibitors for COVID-19 - A miracle waiting to happen or just another beat around the bush? Prim Care Diabetes (2020) 14(5):564-5. doi: 10.1016/j.pcd.2020.05.013

113. Fernandez-Fernandez B, D’Marco L. Exploring Sodium Glucose CoTransporter-2 (SGLT2) Inhibitors for Organ Protection in COVID-19. J Clin Med (2020) 9(7):2030. doi: 10.3390/jcm9072030

114. American diabetes association15. Diabetes Care in the Hospital: Standards of Medical Care in Diabetes-2020. Diabetes Care (2020) 43(Suppl 1):S193-s202. doi: $10.2337 / \mathrm{dc} 20-\mathrm{S} 015$
115. Papadokostaki E, Tentolouris N, Liberopoulos E. COVID-19 and diabetes: What does the clinician need to know? Prim Care Diabetes (2020) 14(5):55863. doi: 10.1016/j.pcd.2020.06.010

116. Bornstein SR, Rubino F, Khunti K, Mingrone G, Hopkins D, Birkenfeld AL, et al. Practical recommendations for the management of diabetes in patients with COVID-19. Lancet Diabetes Endocrinol (2020) 8(6):546-50. doi: 10.1016/S2213-8587(20)30223-0

117. Chen Y, Yang D, Cheng B, Chen J, Peng A, Yang C, et al. Clinical Characteristics and Outcomes of Patients With Diabetes and COVID-19 in Association With Glucose-Lowering Medication. Diabetes Care (2020) 43 (7):1399-407. doi: 10.2337/dc20-0660

118. Mulvihill EE, Drucker DJ. Pharmacology, physiology, and mechanisms of action of dipeptidyl peptidase-4 inhibitors. Endocr Rev (2014) 35(6):9921019. doi: 10.1210/er.2014-1035

119. Fadini GP, Morieri ML, Longato E, Bonora BM, Pinelli S, Selmin E, et al. Exposure to dipeptidyl-peptidase- 4 inhibitors and COVID-19 among people with type 2 diabetes: A case-control study. Diabetes Obes Metab (2020). doi: 10.1111/dom. 14097

120. Strollo R, Maddaloni E, Dauriz M, Pedone C, Buzzetti R, Pozzilli P, et al. Use of DPP4 inhibitors in Italy does not correlate with diabetes prevalence among COVID-19 deaths. Diabetes Res Clin Pract (2020), 108444. doi: 10.1016/j.diabres.2020.108444

121. Cariou B, Hadjadj S. Phenotypic characteristics and prognosis of inpatients with COVID-19 and diabetes: the CORONADO study. Diabetologia (2020) 63(8):1500-15. doi: 10.1007/s00125-020-05180-x

122. Solerte SB, D'addio F, Trevisan R, Lovati E, Rossi A, Pastore I, et al. Sitagliptin Treatment at the Time of Hospitalization Was Associated With Reduced Mortality in Patients With Type 2 Diabetes and COVID-19: A Multicenter, Case-Control, Retrospective, Observational Study. Diabetes Care (2020) dc201521. doi: 10.2337/dc20-1521

123. Monteil V, Kwon H, Prado P, Hagelkrüys A, Wimmer RA, Stahl M, et al. Inhibition of SARS-CoV-2 Infections in Engineered Human Tissues Using Clinical-Grade Soluble Human ACE2. Cell (2020) 181(4):905-913.e7. doi: 10.1016/j.cell.2020.04.004

124. Mozafari N, Azadi S, Mehdi-Alamdarlou S, Ashrafi H, et al. Inflammation: A bridge between diabetes and COVID-19, and possible management with sitagliptin. Med Hypotheses (2020) 143:110111. doi: 10.1016/j.mehy. 2020.110111

Conflict of Interest: The authors declare that the research was conducted in the absence of any commercial or financial relationships that could be construed as a potential conflict of interest.

Copyright (C) 2020 Abu-Farha, Al-Mulla, Thanaraj, Kavalakatt, Ali, Abdul Ghani and Abubaker. This is an open-access article distributed under the terms of the Creative Commons Attribution License (CC BY). The use, distribution or reproduction in other forums is permitted, provided the original author(s) and the copyright owner(s) are credited and that the original publication in this journal is cited, in accordance with accepted academic practice. No use, distribution or reproduction is permitted which does not comply with these terms. 